\title{
Políticas docentes e qualidade da educação: uma revisão da literatura e indicações de política
}

\author{
Adriana Bauer a \\ Nathalia Cassettari ${ }^{b}$ \\ Romualdo Portela de Oliveira ${ }^{a}$
}

\section{Resumo}

O presente artigo discute os aportes do debate acadêmico sobre quatro dimensões relacionadas às políticas docentes no Brasil: atratividade, formação, retenção e avaliação. A partir de revisão de trabalhos que tratam dessas dimensões, muitas vezes isoladamente, objetiva-se destacar os principais problemas a serem equacionados pelas políticas públicas direcionadas aos professores visando à melhoria da qualidade da educação. Para isso, o trabalho divide-se em seis partes: uma introdução, na qual se apresenta a importância da questão docente e os desafios que ela impõe às políticas públicas, e quatro seções, nas quais são analisadas a atratividade, a formação, a retenção e a avaliação de docentes, respectivamente. Ao final sintetizam-se os principais desafios colocados à superação dos problemas destacados.

Palavras-chave: Atratividade docente. Formação docente. Retenção de professores. Avaliação docente.

\section{Introdução}

A busca pela melhoria da qualidade da educação tem-se acentuado nas últimas décadas, impulsionando políticas baseadas no entendimento de que esta não se limita ao acesso e permanência na escola, mas inclui a aprendizagem dos alunos (OLIVEIRA; ARAÚJO, 2005). Com isso, a qualidade dos professores passou à "primeira linha dos fatores críticos a ter em conta para melhorar a educação" (FERNANDES, 2008, p. 11).

\footnotetext{
a Universidade de São Paulo. São Paulo, São Paulo, Brasil.

b Universidade de Brasília. Brasília, Distrito Federal, Brasil. 
Denise Vaillant (2006) afirma que as reformas educacionais impulsionadas em quase todos os países da América Latina nos anos 1990 tiveram como foco modificações na gestão dos sistemas (descentralização administrativa) e no currículo (estabelecimento de parâmetros e diretrizes comuns), sem colocar as políticas docentes em posição de destaque. Tal tendência se modifica com a constatação da insuficiência dessas reformas (DARLING-HAMMOND, 2007; FERNANDES, 2008).

Inúmeras pesquisas apontam a qualidade do professor como o fator interno às unidades escolares que mais influencia a aprendizagem dos alunos. Sobre esse assunto, Darling-Hammond afirma:

Estudantes com sorte suficiente de terem professores que sabem os conteúdos que devem ensinar e a melhor maneira de ensiná-los alcançam resultados substancialmente maiores. Os efeitos de um professor muito bom (ou muito ruim) duram mais do que um ano, influenciando a aprendizagem dos estudantes nos anos seguintes. De fato, professores experts são o recurso mais fundamental para melhorar a educação ${ }^{1}$ (DARLING-HAMMOND, 2007, p. 67).

Auguste, Kihn e Miller (2010, p. 20), reproduzindo afirmação de dirigentes coreanos, afirmam que "a qualidade de um sistema educacional não pode superar a qualidade de seus professores", que se tornou o mantra em torno do qual se discute a necessidade de melhoria do trabalho docente.

Políticas que visem a melhorar a qualidade do corpo docente passaram a ser estimuladas. Para Vaillant (2006, p. 121):

A revisão da literatura em âmbito internacional mostra que as novas expectativas e os desafios, enfrentados pelas sociedade e economias, situam a educação no centro do debate e os professores como atores chave. Neste cenário, os responsáveis educativos enfrentam o desafio constante de dispor de um número suficiente de professores que sejam competentes, que permaneçam motivados e que tenham condições de trabalho adequadas durante sua trajetória profissional

Barber e Mourshed (2007), ao analisarem as características dos sistemas educacionais com melhorias significativas no PISA, destacam que os sistemas

As traduções dos textos citados no original foram feitas pelos autores. 
bem-sucedidos foram aqueles com maior capacidade de atrair, formar e reter bons profissionais para a docência.

Todos os diferentes sistemas escolares que melhoraram significativamente foram mais eficazes em atingir três objetivos: conseguir que mais pessoas talentosas se tornem professores, transformar esses professores em instrutores melhores e garantir que estes professores ensinem consistentemente a cada criança (BARBER; MOURSHED, 2007 p. 43).

O debate sobre Políticas Públicas para o magistério passou a enfocar a atratividade, a formação e a retenção de professores. A esse conjunto foi acrescida, neste trabalho, uma quarta dimensão, a avaliação docente, também tida como elemento importante para se melhorar o corpo docente na literatura especializada. O objetivo deste artigo é discutir a questão docente nessas quatro dimensões.

\section{Atratividade}

$\mathrm{Na}$ escolha profissional há forte influência de fatores como a valorização social da profissão, as condições de trabalho e remuneração, o acesso de diferentes grupos sociais à educação, os custos reais da formação, os requisitos e expectativas de ingresso no mercado de trabalho etc. De acordo com Gatti et al. (2010, p. 9),

[...] o processo de escolha profissional e a inserção no mundo do trabalho são cada vez mais intrincados, geram dilemas, o que significa que as possibilidades de escolha profissional não estão relacionadas somente às características pessoais, mas principalmente ao contexto histórico e ao ambiente sociocultural em que o jovem vive.

Considera-se a dificuldade para o preenchimento das vagas existentes como um indicador do problema quantitativo da atratividade da carreira docente. Isso é sentido em muitos países, cujo número de novos professores não tem sido suficiente para substituir os que saem e os novos que ingressam devido à expansão do sistema.

À primeira vista, poder-se-ia supor que o grande número de estudantes matriculados e formados em cursos de formação de professores ${ }^{2}$ seria outro indicador de que,

\footnotetext{
2 De acordo com o Censo da Educação Superior (BRASIL, 2014), o número de matrículas nos cursos de Licenciatura apresentou crescimento entre os anos de 2009 a 2012 chegando, neste último, a 1.366.559. Só o curso de pedagogia foi o terceiro maior em número de matrículas $(602.998$, ou $8,6 \%$ do total) e o segundo maior em concluintes (112.137, ou 10,7\% do total).
} 
no Brasil, o problema da atratividade não é quantitativo, ou, ao menos, não na mesma medida que em outros países, ainda que possam existir carências em algumas regiões e disciplinas. No entanto, alguns estudos têm mostrado que, mesmo com a ampliação do número de vagas em cursos de formação de professores, tanto na modalidade presencial e, principalmente, em cursos à distância, o percentual de formados que atuarão como professores é inferior ao contingente necessário.

Relatório da Organização para a Cooperação e Desenvolvimento Económico ou Econômico - OCDE (2007) traz evidências de que o problema da escassez de professores é, de maneira geral, maior em áreas remotas e nas periferias das grandes cidades, nas quais residem os estudantes mais vulneráveis, acentuando as desigualdades existentes. Nessas áreas, os professores também tendem a ter menor experiência e qualificação.

Para Ingersoll e Smith (2003, p. 31), "as estatísticas sugerem que a raiz da falta de professores está, em grande medida, nas condições de trabalho nas escolas e nos bairros". Para eles, a superação deste problema deve vir, justamente, da alteração das condições de trabalho, em especial nas áreas mais vulneráveis, de modo que os professores não apenas sejam atraídos por trabalhar nestas regiões, mas que ali permaneçam.

Sem desconsiderar que existem problemas relacionados à distribuição desigual de professores no território e entre as disciplinas escolares, os dados indicam que, no Brasil, a profissão é atraente para uma parcela da população, o que pode ser observado pelo grande número de postos de trabalho disponíveis - o que afasta o risco de desemprego (pelo menos a médio prazo). A maior parte destes postos está no setor público. Isso apresenta vantagens, como a estabilidade no emprego, a aposentadoria integral e, em menor tempo, o maior período de férias e a possibilidade de trabalho em apenas um turno. Ademais, apesar dos salários serem mais baixos do que os de outros profissionais com formação similar, estes vêm aumentando ao longo do tempo (MORICONI, 2008, LOUZANO et al., 2010).

As razões da baixa atratividade da profissão seriam a desvalorização social, os baixos salários, as péssimas condições de trabalho, as escassas oportunidades de crescimento pessoal e a estrutura da carreira, que não aponta grandes perspectivas de crescimento profissional (BARBOSA, 2011GATTI; BARRETTO, 2009; LOUZANO et al., 2010)

Há, ainda, outra dimensão da atratividade que deve ser considerada: a necessidade de serem atraídos candidatos com bom desempenho no ensino médio para que não sejam demandados esforços adicionais que compensem lacunas de formação anterior. 
Entretanto os que se interessam pela profissão apresentam pior desempenho escolar em comparação aos demais alunos do ensino médio (BRASIL, 2009; COLAZINGARI, 2015; LOUZANO et al., 2010). Estudo de Leme (2012) corrobora essa análise. De acordo com a autora, os cursos de licenciatura em física, matemática e pedagogia estiveram entre aqueles com menores notas de corte para a segunda fase da Fuvest. Em trabalho anterior (LEME, 2008), a autora já havia encontrado evidências de um baixo desempenho de ingressantes de pedagogia nesse mesmo vestibular. Segundo ela, em 2007 o curso de pedagogia ficou em terceiro lugar, considerando os cursos com menores médias alcançadas na primeira fase pelos convocados para a primeira matrícula.

Os dados da Fuvest de $2015^{3}$ mostram que candidatos de apenas 16 cursos, de um total de 108, foram aprovados com pontuações menores do que os cursos de pedagogia de São Paulo (36 pontos), sendo que, dos primeiros citados, quatro eram de licenciatura. Já o curso de pedagogia da Universidade de São Paulo de Ribeirão Preto, foi um dos cinco cursos que convocou candidatos com o menor número de pontos (27 pontos).

Marin e Giovanni (2007), ao estudarem a produção e interpretação de textos escritos por alunos concluintes de cursos superiores de formação de professores, destacam a precariedade do domínio de conteúdos escolares básicos (relacionados com a leitura e escrita) considerados essenciais para o desempenho da profissão. Para as autoras "o capital cultural veiculado pela ação da escola, no caso dos formandos, não lhes permitiu superar totalmente o capital cultural familiar [...]. Ou seja, não lhes permitiram adquirir o capital cultural objetivado por excelência, que é a escrita correta" (p. 38).

A literatura indica que a profissão tem atraído a parcela da população com menor background cultural e econômico. É pouco provável que, no Brasil, a curto prazo, consiga se melhorar a qualidade dos professores por meio da atratividade de alunos com melhor perfil cultural e econômico. A alternativa é levar em conta esse fato para modelar os cursos de formação, procurando superar as lacunas de formação básica. Isso incidiria na duração dos cursos de formação e, portanto, em seus custos. Assim, somente seria viável economicamente para o estudante de baixa renda, caso realizada em cursos de formação gratuitos.

Cabe reforçar que a atratividade da profissão está diretamente relacionada a temas como salário ${ }^{4}$, carreira, condições de trabalho e aposentadoria. Ainda que existam

\footnotetext{
3 Disponíveis em: <http://www.fuvest.br/vest2015/informes/fuv_2015_corte.pdf>. Acesso em: maio 2015.

${ }^{4}$ Segundo levantamento divulgado pela Confederação Nacional dos Trabalhadores em Educação (CNTE), em março de 2016, 14 estados pagavam aos professores menos do que os $R \$ 2.135,64$ por mês, definidos como piso nacional do magistério para esse ano.
} 
questões relativas a stress profissional e violência (CODO, 1999), a principal condição para que se aumente a atratividade diz respeito ao aumento dos recursos financeiros alocados no magistério, ou seja, depende de uma consistente decisão de política pública.

\section{Formação}

Desde os anos de 1990, a formação docente tem sido entendida como elemento crucial para a garantia da qualidade de ensino e de aprendizagem dos alunos (GUSKEY, 2009; SOARES et al., 2012) e fator de profissionalização. Apenas uma formação densa pode contribuir com o fortalecimento da profissão e, consequentemente, com a melhoria do status social dos professores, colaborando, também, com a atratividade e retenção na carreira, ao mesmo tempo em que se supõe que esta formação impactaria a qualidade do ensino (NÓVOA, 1992).

Seria preciso considerar que nos momentos em que a demanda por professores é maior do que a sua oferta, os requisitos formativos tendem a ser flexibilizados, como aconteceu, por exemplo, no processo de expansão do ensino no Brasil (VICENTINI; LUGLI, 2009). No entanto, há que se pensar em estratégias que compensem essa maior flexibilidade, visando a propiciar formação adequada aos docentes.

Segundo a OCDE, existem muitas diferenças entre os países, no tocante aos requisitos para o ingresso na profissão e na maneira como a formação profissional acontece:

A formação de professores ocorre em instituições muito diversas: faculdades, universidades de formação de professores, instituições públicas administradas pelo governo e instituições privadas. Em alguns países [...] os estudantes contribuem com os custos da educação de professores, na forma de taxas educacionais. Em outros [...] a educação de professores é gratuita. Em muitos países europeus, o ingresso em programas de educação de professores é aberto a todos que tiverem concluído o ensino médio, ao passo que em outros países as oportunidades de ingresso são mais restritivas [...]. Em países onde a docência tem alto status social - como Coréia do Sul, Finlândia e Irlanda-, há uma competição acirrada para o ingresso em programas de educação de professores (OCDE, 2007, p. 107). 
No Brasil é possível observar um desenvolvimento lento dos requisitos formais para ingresso na profissão. O artigo 62 da LDB (BRASIL, 1996a) determina que a formação dos professores para a educação básica, seja em nível superior, admitida, para a educação infantil e para as séries iniciais do ensino fundamental, a formação em nível médio, na modalidade Normal. Disso resultou um aumento significativo do nível de escolaridade dos docentes brasileiros. Dados do Censo Escolar mostram que o percentual de professores da educação básica com Ensino Superior completo passou de $68,4 \%$, em 2007, para mais de $74 \%$ em 2013 (BRASIL, 2014).

Cabe destacar, ainda, que políticas educacionais implantadas desde meados da década de 1990 destinaram boa parte dos recursos disponíveis à formação e ao desenvolvimento dos professores, como foi o caso do Fundo de Manutenção e Desenvolvimento do Ensino Fundamental e de Valorização do Magistério (Fundef), instituído pela Emenda Constitucional no ${ }^{\circ}$ 14, de 12 de setembro de 1996 (BRASIL, 1996b), criado por iniciativa do governo federal, e que vinculou $15 \%$ do total de impostos à educação fundamental. Destes recursos, $60 \%$ (ou seja $9 \%$ da receita de impostos) foram subvinculados à formação dos professores, ampliando consideravelmente a possibilidade de as redes municipais e estaduais de ensino designarem recursos ao desenvolvimento profissional dos docentes ${ }^{5}$. $\mathrm{Na}$ época, o Manual de Orientação do Fundef, elaborado pelo governo federal, justificou assim essa medida:

A atualização e o aprofundamento dos conhecimentos profissionais deverão ser promovidos a partir de programas de aperfeiçoamento profissional continuado, assegurados nos planos de carreira do magistério público. Para esse fim, podem ser usados os recursos da parcela dos $40 \%$ do Fundef, inclusive no desenvolvimento da formação em nível superior dos professores que atuam na docência de $1^{\mathrm{a}}$ a $4^{\mathrm{a}}$ série do ensino fundamental público, obedecendo, nesse caso, às exigências legais estabelecidas (BRASIL, 2004, p. 25).

A lógica do Fundef foi mantida pelo Fundo de Manutenção e Desenvolvimento da Educação Básica e de Valorização dos Profissionais da Educação (Fundeb), criado pela Emenda Constitucional n ${ }^{\circ}$ 53, de 6 de dezembro de 2006 (BRASIL, 2006) que, entretanto, ampliou a subvinculação de recursos para toda a Educação Básica, atendendo aos professores da creche ao Ensino Médio. Por meio dos recursos desse fundo, programas como o Pró-Licenciatura, Pró-Letramento,

\footnotetext{
5 Não se pretende afirmar que o aumento das atividades de formação continuada deve-se unicamente ao Fundef, mas sim destacar que os recursos disponibilizados pelo Fundo, para o gasto com o Magistério, foram importantes para a concretização de atividades de formação docente inicial e contínua.
} 
Pró Formação e Rede Nacional de Formação Continuada de Professores, entre outros, foram concebidos pelo governo federal e implementados por estados e municípios com o objetivo de melhorar a qualificação dos profissionais do magistério público brasileiro em todos os níveis de ensino.

Os avanços do período são inegáveis neste particular. Entretanto, permanecem desafios complexos a serem superados para que se atenda às exigências impostas pela legislação, especialmente quando consideradas as diferenças entre as regiões brasileiras e as disciplinas que compõem o currículo da educação básica, que são mais acentuados nas regiões Norte e Nordeste e nas disciplinas associadas às ciências exatas.

\subsection{Características dos cursos}

No Brasil, observa-se a participação cada vez maior da iniciativa privada na oferta de cursos de formação inicial de professores, em especial em cursos à distância, conforme indicam os dados do Censo da Educação Superior (Tabela).

Tabela. Número de Matrículas de Graduação em Licenciatura ${ }^{6}$ por Modalidade de Ensino e Categoria Administrativa. Brasil, 2003-2012.

\begin{tabular}{lccccc}
\hline \multirow{2}{*}{ Ano } & \multirow{2}{*}{ Total } & \multicolumn{2}{c}{ Presencial } & \multicolumn{2}{c}{ A distância } \\
\cline { 3 - 6 } & & Pública & Privada & Pública & Privada \\
\hline 2003 & 885.384 & 385.516 & 452.677 & 39.804 & 7.387 \\
2004 & 928.599 & 391.276 & 485.864 & 35.989 & 15.470 \\
2005 & 970.331 & 373.745 & 518.184 & 43.430 & 34.972 \\
2006 & 1.023 .582 & 365.779 & 507.995 & 37.746 & 112.062 \\
2007 & 1.062 .073 & 359.895 & 486.450 & 47.889 & 167.839 \\
2008 & 1.159 .750 & 352.594 & 466.038 & 101.492 & 239.626 \\
2009 & 1.191 .763 & 361.245 & 410.424 & 97.523 & 322.571 \\
2010 & 1.354 .989 & 458.737 & 470.011 & 102.984 & 323.257 \\
2011 & 1.356 .329 & 483.544 & 443.236 & 104.785 & 324.764 \\
2012 & 1.366 .559 & 495.663 & 420.930 & 108.820 & 341.146 \\
\hline
\end{tabular}

Fonte: BRASIL, 2013.

\footnotetext{
6 No Censo da Educação Superior (BRASIL, 2013) os cursos de graduação são divididos em: Bacharelado, Licenciatura, Tecnológico, Bacharelado e Licenciatura, e Não Informado. Optou-se pela apresentação apenas dos dados referente aos cursos de Licenciatura por serem considerados suficientes para ilustrar o movimento referente aos cursos de formação de professores no Brasil.
} 
Segundo os dados apresentados na Tabela, houve um crescimento das matrículas dos cursos de licenciatura, tanto em instituições públicas quanto privadas. No período analisado, a participação do setor privado passou de $52 \%$ para $56 \%$, evidenciando um crescimento mais acentuado, principalmente no ensino a distância, passando de $1,6 \%$ para $44 \%$.

Com raras exceções, as instituições privadas são percebidas como de pior qualidade, o que se explica, ao menos em parte, pelo "boom mal regulamentado dessas instituições" (LOUZANO et al., 2010, p. 557). As Sinopses Estatísticas da Educação Superior, de 2013, referentes a todos os cursos de graduação, apresentam dados que ajudam a reforçar tal percepção: o percentual de professores doutores é maior em instituições públicas federais $(57,8 \%)$ e estaduais $(48,1 \%)$ do que nas privadas $(17,8 \%)$, e o percentual de faculdades isoladas "em que as oportunidades de trocas culturais tendem a ser mais pobres" (Gatti; Barreto, 2009, p. 59) é menor nas instituições públicas federais $(3,77 \%)$ e estaduais $(67,22 \%)$ do que nas privadas $(89,76 \%)$.

O processo de transformação de um número significativo de universidades privadas em grandes empresas, com mais de 100 mil alunos algumas delas, resultou na expansão de seus campi por diferentes estados e regiões do país, mas o sucesso empresarial que obtiveram parece não ter sido acompanhado de um correspondente amadurecimento acadêmico e do desenvolvimento efetivo da capacidade de criação de conhecimentos novos por meio de pesquisa, que constitui o cerne das atividades de caráter propriamente universitário. (GATTI; BARRETTO, 2009, p. 59)

Ainda são escassos os estudos sobre a qualidade dos cursos a distância. A qualidade da formação que tem sido ofertada é questionada, e as potenciais contribuições dessa modalidade à formação profissional são relativizadas, visto que não se desenvolveram ferramentas, no âmbito dos órgãos federais, que organizam e regulamentam o ensino superior no país, de acompanhamento e avaliação desses cursos.

\subsection{Qualidade da formação}

Gatti e Nunes (2009) analisaram os currículos dos cursos de formação de professores e identificaram diversas lacunas, em especial, a pouca relação das disciplinas com a prática docente e com o contexto concreto de atuação dos futuros professores. Além disso, encontraram problemas na maneira como os estágios estão organizados (sem especificação sobre em que consistem e à maneira como são realizados), muitas horas 
dedicadas a atividades complementares e culturais (sem a devida explicitação quanto a que se referem, aos seus objetivos e à maneira como são realizadas) e pouco ou nenhum espaço nos currículos para tratar de alguns níveis e modalidades de ensino, como a EJA, a Educação Especial e a Educação Infantil. Em pesquisa posterior, além dos fatos apontados, as autoras afirmam que se percebe um:

[...] predomínio de formação acadêmica, mais abstrata, de caráter excessivamente genérico, nas proposições institucionais para essa formação. Não que esse tipo de formação não seja necessário, mas ele é insuficiente para a integralização da formação de um(a) profissional da docência. Pelas normas vigentes no Brasil, definem-se espaços nas licenciaturas, destinados ao tratamento concreto das práticas docentes, nos quais se poderia aliar experiência e teoria. Porém, esses espaços não são utilizados de fato nas instituições formadoras, para fazer essa rica aliança entre conhecimento acadêmico e conhecimento que vem com o exercício da profissão e as experiências vividas em situações escolares na educação básica. Encontramos, sobre esse aspecto, uma dissonância entre o proposto legalmente e o realizado (Gatti; Barretto; Andre, 2011, p. 91).

Segundo as autoras, os cursos, da forma como estão organizados, têm contribuído pouco para a melhoria da qualificação docente e ainda "favorecem o desgaste da própria identidade profissional desses trabalhadores" (GATTI, BARRETTO; ANDRÉ, 2011, p. 117), o que tem efeitos negativos para a valorização da profissão.

No que se refere à formação continuada, é possível afirmar que seu principal propósito é "a atualização e aprofundamento de conhecimentos como requisito natural do trabalho em face do avanço nos conhecimentos, as mudanças no campo das tecnologias, os rearranjos nos processos produtivos e suas repercussões sociais" (GATTI; BARRETTO, 2009, p. 200).

Entretanto, devido aos crescentes problemas dos cursos de formação inicial de professores "a ideia de formação continuada como aprimoramento profissional foi-se deslocando para uma concepção de formação compensatória destinada a preencher lacunas da formação inicial" (GATTI; BARRETTO, 2009, p. 200). Nesse sentido, a formação continuada perde, aos poucos, seu caráter de melhoria da qualificação do profissional para tornar-se uma formação básica emergencial.

Assim, o aumento dos anos de escolaridade dos professores brasileiros não foi suficiente para suprir as suas necessidades formativas, o que traz novos desafios para 
as políticas educacionais. Mais ainda, essa prescrição legal privatizou a formação docente para instituições privadas de baixa qualidade, estabelecendo um ciclo perverso, o magistério atrai candidatos com menos background cultural, que são formados em instituições de pior qualidade, que retornam como professores para uma escola pública já precarizada. Melhorar a educação, em primeiro lugar, significa enfrentar o desafio de romper com esse ciclo que apenas exacerba a piora da qualidade.

\section{Retenção}

Tendo em vista o elevado número de pedidos de demissão de professores, tanto para se alocar em outras funções na estrutura do sistema de ensino, quanto para abandonar a profissão, a temática da retenção tem-se tornado uma questão de política docente. Muitos dos fatores identificados como fundamentais para tornar a docência mais atraente também podem incentivar a permanência dos professores na profissão. Nesse sentido: "Salários competitivos, boas condições de trabalho, satisfação no trabalho e oportunidades de desenvolvimento aumentarão o apelo da docência, tanto para novos professores, quanto para equipes já empregadas" (OCDE, 2007, p. 180).

Ingersoll e Smith (2003) identificam duas vertentes no debate sobre a retenção dos professores: uma que discute o abandono (attrition) - professores deixam a profissão para exercerem outras atividades - e outra que discute a rotatividade, (migration) - professores permanecem na profissão, mas mudam de escola de um ano para o outro.

Existem diferenças entre os professores que largam a docência para se dedicar a outras funções dentro do sistema educacional (coordenação, direção, supervisão etc.) e aqueles que se transferem para outras ocupações (remuneradas ou não). Em diferentes países, identificam-se as mesmas razões como fundamentais para o abandono do trabalho docente: salário, carreira, condições de trabalho e motivações pessoais. Na maioria dos casos, entretanto, essa decisão não se limita a um único fator, envolvendo diferentes questões que, muitas vezes, se relacionam (OCDE, 2007).

Farber (2010), nos EUA, aponta outros aspectos: clima de trabalho e pressões oriundas dos testes de alto impacto, violência nas escolas e sensação de insegurança, altas e irreais expectativas depositadas sobre os professores, quer pelos governos, quer pelos pais, falta de respeito pelo trabalho desenvolvido.

Com relação à rotatividade, destacam-se os estudos que procuram entender $o$ movimento dos professores ao longo da carreira, notadamente, das periferias para o centro, ou do rural para o urbano, como aliás, já evidenciado, para o caso 
brasileiro, no trabalho clássico de Pereira (1969) sobre o magistério, o que traz profundas implicações para a manutenção das desigualdades educacionais e sociais e, consequentemente, para a qualidade da educação.

A reposição de professores gera custos altos para os sistemas de ensino. De acordo com estimativas elaboradas por Ingersoll para publicação da Alliance for Excellent Education (2014), as redes estaduais dos Estados Unidos gastaram, juntas, de 1 a 2,2 bilhões de dólares com a reposição de professores, só nos anos letivos de 2008/2009.

Esses custos, somados a outros ainda mais sérios - como os prejuízos para a aprendizagem dos alunos - sugerem que a retenção dos professores na profissão seja tratada com urgência pelas políticas educacionais. Os problemas relacionados com a baixa retenção de professores são sintetizados pela OCDE da seguinte maneira:

As escolas e os sistemas envolvidos são obrigados a arcar com os custos de captação, recrutamento e iniciação de grande número de novos professores; os estudantes enfrentam alta reposição de professores e possivelmente perdem em termos de continuidade de programa; e a constatação de que as taxas de vacância são maiores em localidades pouco favorecidas sugere que há um acúmulo de problemas educacionais e um aumento da desigualdade entre as escolas (OCDE, 2006, p. 186).

No Brasil, estudos que analisam questões relacionadas com a retenção de professores são escassos, o que, ao menos em parte, se deve à dificuldade de obtenção de dados que permitam acompanhar o percurso de cada professor ao longo de sua vida profissional, sendo ainda mais difícil a obtenção de dados sobre os professores que pediram exoneração. Outro motivo pode ser atribuído ao grande número de professores precários e temporários, uma vez que "fica difícil saber se esses professores não estão mais na rede por vontade própria ou por falta de vagas" (LAPO; BUENO, 2003, p. 68).

\subsection{Abandono}

Segundo dados do jornal Estado de São Paulo ${ }^{7}$, entre 2008 e 2012, a média de pedidos de exoneração na rede estadual de São Paulo foi de 3.000 por ano ${ }^{8}$, equivalente a oito professores por dia. Em Minas Gerais, de acordo com o jornal

\footnotetext{
Disponíveis em: <http://educacao.estadao.com.br/noticias/geral,por-ano-3-mil-professores-desistem-dedar-aula-nas-escolas-estaduais-de-sp,1069886|> . Acesso em: maio 2015.

8 O número apresentado é muito superior ao encontrado por Lapo e Bueno (2003) entre os anos de 1990 e 1995, quando o total de pedidos de exoneração na rede estadual de Educação de São Paulo foi de 1.850. Na ocasião, as autoras já atentavam para um crescimento médio anual de $43 \%$ nos pedidos de exoneração.
} 
O Tempo ${ }^{9}$, foram 1.283 pedidos de exoneração na rede estadual entre janeiro e agosto de 2012, número que superou o total de pedidos de todo o ano anterior e representa uma média de cinco professores por dia. Já na rede estadual do Rio de Janeiro, conforme divulgado no portal Terra ${ }^{10}$, foram 308 pedidos de exoneração só nos primeiros cinco meses de 2013, quase três por dia.

As notícias acima apresentam os baixos salários como principal motivo para a exoneração, ressaltando, de maneira alarmante, que o número de contratações não tem sido suficiente para suprir a demanda.

Destacam-se, na literatura analisada, dois estudos sobre características e motivações de professores que abandonam a docência. O de Lapo e Bueno (2003), com dados da rede estadual paulista, e o de Cassettari, Frutoso e Scaldelai (2014), com dados de Diadema e São Bernardo do Campo. Em ambos, os entrevistados (amostras não probabilísticas) apresentam maior titulação no momento de exoneração do que no de entrada. Sobre o tempo decorrido entre o ingresso e o pedido de exoneração, em Diadema a maioria dos professores pediu exoneração antes de completar 5 anos na rede, corroborando tendência apresentada pela OCDE (2007), enquanto que, tanto em São Bernardo do Campo, quanto em São Paulo, a maioria dos professores pediu exoneração depois de cinco anos na rede, sendo alto o percentual de professores que nela permaneceu por pelo menos 10 anos.

Ao analisarem as ocupações posteriores ao pedido de exoneração, Cassettari, Frutoso e Scaldelai (2014) constataram diferenças que podem ajudar a explicar por que o tempo de permanência nas redes foi tão diferente. Em Diadema, a maioria dos professores deixou uma rede para se tornar professor em outra rede de ensino, enquanto, em São Bernardo do Campo, a maioria pediu exoneração para exercer outros cargos dentro da mesma rede de ensino (direção, coordenação, assistente de direção).

O abandono da docência em busca de funções mais bem remuneradas é uma característica presente na carreira do magistério de diferentes países, cuja ascensão na carreira,

[...] implica a realização de tarefas diferentes das que vinham desenvolvendo, em um cargo distinto que, por sua vez, tem sua estrutura salarial vinculada à sua especificidade.

\footnotetext{
Disponíveis em: <http://www.otempo.com.br/cidades/cinco-professores-se-demitem-por-dia-das-escolasestaduais-1.717680>. Acesso em: maio 2015.

10 Disponíveis em: <http://noticias.terra.com.br/educacao/por-dia-quase-tres-professores-pedem-demissaoda-rede-estadual-do-rj,8c0813f70e2ae310VgnVCM4000009bcceb0aRCRD.html>. Acesso em: maio 2015.
} 
Em outras palavras, não se considera a possibilidade de continuidade em uma mesma função para estimular os professores que o desejarem a permanecer em seus cargos, sem serem obrigados a aspirar a outros postos para obter maior remuneração. De fato, isto implica que a carreira profissional docente não dá oportunidades a quem queira alcançar uma distinção profissional, junto com o correspondente reconhecimento salarial, sem deixar suas atividades dentro do curso para assumir uma posição administrativa, de direção ou supervisão (Morduchowicz, 2003, p. 12).

Ao se referir às políticas docentes na América Latina, Vaillant (2005, p. 43) expressa, de maneira semelhante, que:

As condições de trabalho referem-se a uma carreira docente formada piramidalmente por uma série de cargos que supõem diferentes funções, existindo uma só via para aumentar o salário, que é ascender na escala hierárquica do sistema educacional. Para um docente de classe, só há uma melhora substancial de sua renda: passando a diretor da escola e, daí, a supervisor. Ou seja, só se permite a ascensão a outros postos mediante o afastamento da classe, o que tem como consequência perversa o abandono da tarefa de ensinar por parte dos bons professores.

Voltando aos dados sobre os professores que pediram exoneração, percebe-se, em ambos os estudos, que fatores similares influenciaram esta decisão. A baixa remuneração foi apontada como principal motivo que levou à exoneração, em geral acompanhada de outros elementos relacionados, principalmente, com a ausência de perspectivas de crescimento profissional e com as condições de trabalho "aspectos claramente decorrentes do modo como o Estado gere a educação e o ensino público" (LAPO; BUENO, 2013, p. 73).

Cassettari, Frutoso e Scaldelai (2014) indicam a "remuneração" como o fator que mais influenciou os professores a ingressarem e a pedirem exoneração das redes de ensino, o que pode indicar problemas nos planos de carreira, que vão perdendo a atratividade. Esta hipótese é analisada por Gabriela Moriconi (2008) na comparação que realiza entre o salário dos professores públicos com o salário de outros profissionais do setor público e do setor privado em diferentes momentos da carreira. A autora constatou que:

No período estudado, alguns grupos de professores públicos tiveram remunerações relativamente melhores ou apenas um pouco menores do 
que outras ocupações no início da carreira, o que pode atrair indivíduos para a profissão do magistério. Porém para aqueles que já estavam nos últimos anos da carreira, essas remunerações se mostraram bem menos competitivas. Isto pode gerar o abandono da carreira por aqueles que fizeram a escolha pelo magistério ou a falta de motivação e a busca por trabalhos secundários, o que pode atrapalhar o desempenho dos professores públicos no processo de ensino (p. 64).

Para Lapo e Bueno (2003), o abandono do trabalho docente é o desfecho de um processo que se concretiza ao longo de vários anos, nos quais os vínculos com a profissão vão-se enfraquecendo por conta de uma série de insatisfações, fadigas, descuidos e desprezos. As autoras perceberam que antes do abandono definitivo, os professores se foram se afastando emocional e fisicamente do ambiente de trabalho, utilizando-se de diferentes mecanismos, dentre os quais: os abandonos temporários (faltas e licenças curtas), a acomodação (indiferença com relação a tudo que acontece no ambiente escolar) e a remoção (troca constante de escolas), aspecto que discutiremos no próximo item.

\subsection{Rotatividade}

Em muitos sistemas, a rotatividade acontece por meio dos concursos de remoção, quando os professores podem transferir-se de escola sem alterar seu vínculo empregatício.

De acordo com Silva (2007), a permanência ou não de um professor em uma dada escola pode decorrer de condicionantes institucionais (aqueles que estão sujeitos à organização administrativa do Estado) e/ou psicossociais (que dizem respeito às ações do indivíduo e seu comportamento dentro da organização). Esses condicionantes são: localização da escola, condições de trabalho (número de alunos por turma, materiais e equipamentos disponíveis, conservação do espaço, índices de violência etc.), relacionamento com a equipe escolar, nível de concordância com o modelo de gestão ou linha pedagógica adotada.

A remoção pode ser entendida como uma estratégia para fugir de determinadas situações ou ambientes considerados desagradáveis. Entretanto, nem sempre a remoção tem o efeito esperado, já que o professor pode acabar encontrando dificuldades ainda mais complexas (LAPO; BUENO, 2003).

A rotatividade compromete a continuidade do trabalho pedagógico e a possibilidade de trabalho em equipe, o que, por sua vez, interfere na aprendizagem dos alunos. Tal problema é colocado por Silva (2007) da seguinte maneira: 
O problema que ora se apresenta é, em havendo uma grande rotatividade de professores anualmente, sendo parte substituída por outros, ainda se tem professores para ensinar aos alunos, mas perdem-se as relações construídas anteriormente [de socialização e trabalho coletivo] causando a interrupção do processo de ensino-aprendizagem.

Biondi e Felício (2007) encontram correlação entre a rotatividade dos professores e o desempenho dos alunos da $4^{\text {a }}$ série do ensino fundamental no Sistema de Avaliação da Educação Básica (SAEB).

[...] observa-se que turmas que tiveram a disciplina de Matemática durante todo o ano letivo com o mesmo professor, ou seja, que não tiveram problema com rotatividade de professores, levam ao melhor desempenho médio na escola. [...] Turmas que tiveram somente um professor de Matemática ao longo do ano letivo apresentam um desempenho de 4,2 pontos maior relativamente às turmas que tiveram mais de um professor de Matemática, demonstrando que a redução da rotatividade dos professores nas turmas pode ser alvo de políticas para melhorar o desempenho dos alunos e a qualidade da educação (p. 16).

Paul e Barbosa (2007) analisaram o resultado de alunos de $4^{\mathrm{a}}$ série em avaliações em larga escala aplicadas em 4 cidades da América Latina (situadas no Brasil, Argentina, Chile e México), chegando a resultados semelhantes, indicando que "professores que têm menor rotatividade, isto é, que permanecem mais tempo na mesma escola, também têm alunos que obtêm melhores resultados nos testes aplicados" ( $\mathrm{s} / \mathrm{p})$. Os autores também encontraram evidência da relação entre a rotatividade dos professores e o nível socioeconômico dos alunos, assim "os alunos menos favorecidos socialmente são aqueles que são ensinados por professores menos experientes e com maior nível de rotatividade" $(\mathrm{s} / \mathrm{p})^{11}$. Com base nos dados da pesquisa, concluem que:

[...] nesses quatro países os mecanismos de alocação de professores nas escolas públicas tendem a reforçar a desigualdade de oportunidades educacionais. Para políticas públicas que se pretendam eficientes e equânimes este resultado é um desastre! Nega-se a igualdade de oportunidades educacionais, especificadas aqui como o acesso a bons professores, justamente aos alunos que

\footnotetext{
${ }^{11}$ Luiz Pereira, em 1963, já apresentava o movimento das professoras primárias de São Paulo em direção às regiões centrais influenciado por uma série de questões (tais como a proximidade da família e o maior acesso a bens culturais). A disputa pelas vagas centrais garantia uma maior estabilidade do corpo docente e uma maior experiência dos profissionais (já que professoras em início de carreira muito provavelmente não conseguiriam ocupá-las) justamente nas escolas cujos alunos possuíam melhores condições socioeconômicas.
} 
dela mais dependem para sua inserção adequada na sociedade. As evidências de pesquisa demonstram que professores mais experientes são mais capazes de ensinar os alunos mais "difíceis" e mais carentes. Numa combinação perversa, que merece maiores investigações, as políticas de distribuição de professores e os esforços de alocação de cada um deles nas melhores escolas acabam levando ao pior efeito possível. Os alunos que mais necessitam professores experientes e estáveis são os que recebem os professores menos experientes e com maior rotatividade. Em países que são tão desiguais, os sistemas escolares parecem estar contribuindo para aprofundar essas desigualdades sociais. Ironicamente, essa contribuição está associada ao grupo de agentes sociais cujo discurso tem os tons mais críticos em relação ao funcionamento das escolas e às políticas educacionais, os professores.

Desta forma, seria aconselhável que os sistemas de ensino buscassem estratégias para manter os professores em uma só escola. Entretanto, uma questão se destaca: como resolver o problema da rotatividade sem alterar os direitos já conquistados pelos professores e normatizados pelos órgãos públicos? (SILVA, 2007).

Essa questão torna-se ainda mais relevante se considerarmos que, "quando, por quaisquer razões, o professor não quer ou não pode fazer uso dos abandonos temporários ou da remoção, ou, mesmo quando faz uso desses abandonos e os conflitos não são eliminados, a sua frustração e a sua insatisfação com o trabalho aumentam" (LAPO; BUENO, 2003, p. 83). Segundo as autoras, essa situação pode levar ao abandono definitivo da profissão, ao burnout - "expressão utilizada por autores estrangeiros para designar o fenômeno de estresse acentuado dos professores" (p. 83) ou ainda à acomodação - "entendida como o distanciamento da atividade docente mediante condutas de indiferença a tudo que ocorre no ambiente escolar, ou de um tipo de inércia, no sentido de buscar inovações e melhorias no ensino" (p. 84). Cabe, inclusive, registrar a ausência, até o presente momento, de políticas públicas destinadas ao problema.

\section{Avaliação}

A avaliação constitui outra dimensão do debate acerca dos docentes. Iniciativas de avaliação docente têm sido legitimadas por instrumentos legais propostos pelo próprio Ministério da Educação que permitem, inclusive, a utilização de instrumentos de aferição de conhecimentos e habilidades cognitivas, e a incorporação de mecanismos de acompanhamento da atuação profissional em propostas voltadas à avaliação de docentes. 
Na bibliografia analisada encontram-se inúmeras possibilidades para a avaliação de professores, relacionadas aos objetivos, critérios e padrões de performance utilizados, e à maneira como os dados são recolhidos e analisados (por quê, o que e como avaliar) (BARREIRA; REBELO, 2008; BAUER, 2012; 2013; GATTI, 2011). Os diferentes modelos são utilizados de acordo com o contexto em que estão inseridos (características do sistema de ensino, grau de organização e mobilização dos sindicatos e associações de professores, oferta e demanda de profissionais etc.), as concepções e interesses dos envolvidos no processo e a correlação de forças entre eles.

Foram encontradas algumas recomendações consensuais na literatura, como incluir diferentes atores (principalmente os professores) nos momentos de avaliação; garantir que o processo avaliativo seja viável, confiável, válido e útil; basear a avaliação em critérios claros, previamente estabelecidos e amplamente divulgados; utilizar diferentes instrumentos para a coleta de dados sobre o trabalho docente; atentar para a conjuntura em que a avaliação acontece. Contudo, em muitos casos essas recomendações são ignoradas pelos formuladores das avaliações.

No Brasil, a avaliação dos professores das instituições públicas está prevista em muitos mecanismos legais, abrangendo diferentes momentos e aspectos da carreira, dentre eles: a seleção e contratação de profissionais (Art. 37, § $2^{\circ}$ e Art. 206, § $4^{\circ}$ da CF/1988 [BRASIL, 1988]). a garantia de estabilidade (Art. 41 da CF/1988) e a progressão salarial (Art. 67 da LDB/1996 [BRASIL, 1996a] e Resolução $n^{\circ}$ 2/2009 do CNE/CEB). Além disso, nos últimos anos houve a proliferação de iniciativas de bonificações vinculadas aos resultados de avaliações em larga escala em diversas redes de ensino ${ }^{12}$.

Os concursos para seleção e contratação de professores acontecem desde o Período Colonial, mas foram se transformando, especialmente durante o Período Republicano, tornando-se mais estruturados e burocratizados. Nesses processos, critérios associados à moralidade dos professores vão perdendo importância, enquanto emergem aqueles ligados ao seu conhecimento (aferido por meio de provas) e à sua titulação (VICENTINI; LUGLI, 2009).

De acordo com Moriconi (2013) os concursos públicos de provas e títulos são amplamente aceitos no Brasil, por se basearem em critérios "justos" e "transparentes". Quando o tema aparece na literatura sobre políticas docentes, "o debate gira em torno de 'como' os concursos devem ser realizados, e não 'se' devem ser realizados" (MORICONI, 2013, p. 185). Como justificativa para

\footnotetext{
${ }^{12}$ A bonificação não é uma política de avaliação de professores, mas um modelo de gestão de pessoal que se utiliza de um tipo de avaliação para estabelecer políticas de incentivo (CASSETTARI, 2010).
} 
tamanho consenso, a autora remete à história das relações sociais no Brasil e à falta de confiança na formação inicial de professores.

Especialmente em países que, assim como o Brasil, ainda não foram capazes de superar satisfatoriamente o patrimonialismo, os processos de ingresso na carreira docente centralizados têm a grande vantagem da impessoalidade e da transparência dos critérios de seleção, bem como da garantia do emprego mesmo durante as transições políticas - viabilizando a continuidade das políticas públicas e não permitindo a barganha de cargos. Essa proteção contra o favoritismo na seleção de docentes parece ser uma razão muito forte para o consenso em torno dos concursos públicos no pais. Aliada a esse fator está outra questão: a falta de confiança na qualidade da formação inicial dos docentes no país. Esse problema levaria a uma maior necessidade de um processo de seleção que verifique se os candidatos estariam, de fato, preparados para a docência -o que atualmente não seria garantido pela simples apresentação de um diploma referente à formação exigida pela legislação vigente em relação aos docentes da educação básica (MORICONI, 2013, p. 187).

Gatti, Barreto e André (2011) questionam a qualidade e validade dos concursos para selecionar professores, uma vez que a formulação das provas nem sempre respeita requisitos básicos, como estar ancorada em um perfil profissional previamente definido, com itens de dificuldade bem dosados (pré-testados e analisados por especialistas), com uma redação cuidadosa (sem ambiguidades) etc. Além disso, ao analisarem o seu conteúdo, concluíram que as provas:

[...] têm majoritariamente questões relativas à legislação e normas, com parte pequena sobre questões pedagógicas e conteúdos específicos da educação básica. Encontram-se poucas questões sobre os fundamentos da educação, e são quase totalmente ausentes questões sobre prática docente, didática e metodologias de ensino (GATTI; BARRETO; ANDRÉ, 2011, p. 156 e 157).

Além das provas, os concursos públicos avaliam os títulos dos candidatos ao magistério, sendo que "usualmente os títulos dizem respeito à formação acadêmica, experiência profissional, publicações de artigos, premiações, aprovações em outros concursos da mesma natureza, dentre outros." (MORICONI, 2013, p. 209). A autora atenta para o fato dos títulos valorizarem conhecimentos, habilidades e competências presumidas (e não comprovadas na prática profissional) e para a 
necessidade dos sistemas de ensino tomarem cuidado para não prejudicarem os mais jovens e aqueles que por razões socioeconômicas tiveram menores chances de abastecer os seus currículos.

Novaes assinala que essas avaliações utilizam critérios semelhantes aos aplicados a qualquer servidor público (pontualidade, assiduidade etc.) e, portanto, não contemplam as especificidades do trabalho docente. Além disso, quando são incluídos critérios como "eficiência" e "comprometimento", isso é feito sem "a determinação de indicadores mais precisos para caracterizá-los" (2013, p. 113).

A avaliação de desempenho constitui uma das condições para a progressão na carreira. No entanto, apesar da maioria dos novos planos de carreira (aprovados após a LDB/96 [BRASIL, 1996a]) preverem esse dispositivo, a quase totalidade "ainda não implementou o processo por falta de regulamentação" (p. 31), o que é resultado de uma série de resistências impostas, principalmente, pelos professores. ${ }^{13}$

Dentre os que implantaram ou estão em processo de implantação de tais avaliações, destaca-se que, em geral, elas se baseiam em critérios muito limitados (assiduidade, pontualidade, participação em programas da secretaria etc.), incapazes de captar todos os aspectos que devem ser considerados para se aferir um bom ou mau desempenho docente.

A rede estadual de São Paulo, em 2009, e da Bahia, em 2008, incorporaram à avaliação do desempenho dos professores, mecanismos de aferição dos seus conhecimentos (por meio de provas) ${ }^{14}$. Apesar de existirem poucos trabalhos que analisam essas iniciativas, uma crítica recorrente refere-se à limitação do número de professores que podem passar para os patamares mais elevados da carreira e, assim, mesmo que um determinado professor comprove que possui os conhecimentos necessários, não necessariamente ele receberá a recompensa devida. Além disso, critica-se o fato de o conteúdo cobrado nessas provas ser muito parecido ao já demonstrado nos concursos públicos de ingresso e possuir pouca relação com o trabalho desenvolvido em sala de aula.

Por fim, destacam-se as iniciativas que premiam os professores das escolas que alcançarem melhores desempenhos (representado tanto por resultados absolutos, quanto por maiores evoluções) em avaliações em larga escala (Prova Brasil e/ou similares) ou em Índices de Desenvolvimento da Educação (IDEB e/ou similares).

\footnotetext{
${ }^{13}$ BALZANO, S. Estudo dos planos de carreira e remuneração do magistério da educação básica dos estados brasileiros. Documento elaborado para o CONSED, jul. 2005. Mimeo.

14 Tais iniciativas são melhor analisadas em Cassettari, 2010.
} 
Levantamento realizado por Nogueira, Jesus e Cruz (2013), identificou sete redes estaduais que adotam tais práticas: Amazonas, Tocantins, Pernambuco, Ceará, São Paulo, Rio de Janeiro e Espírito Santo. Bauer (2013) aponta outros estados com esse tipo de iniciativa: Bahia e Minas Gerais, além do município de Florianópolis.

As principais críticas direcionadas às iniciativas de premiação docente referem-se à possibilidade de incentivarem comportamentos questionáveis (como fraudes, redução do currículo, seleção e exclusão de alunos etc.), à ausência de mecanismos que diferenciam os professores de uma mesma escola, e, no fato de se basearem na ideia de que o incentivo financeiro, por si só, melhoraria a performance dos professores, desconsiderando, assim, a imensa gama de fatores que influenciam tal desempenho.

Em suma, os sistemas educacionais brasileiros têm privilegiado iniciativas que pouco dialogam com o trabalho efetivamente desenvolvido em sala de aula e pouco contribuem para a identificação do que está indo bem e do que pode melhorar e, menos ainda, para a elaboração de ações que ajudem os professores a aprimorar o seu trabalho.

Entretanto, este é o aspecto que tem recebido mais atenção nas políticas voltadas para os docentes, ainda que a eficiência e a eficácia de tais iniciativas longe estejam de ser comprovadas pela experiência. A literatura sobre o tema, para dizer o mínimo, é controversa. É sintomático que se enfatize exatamente aquela faceta que pode ser "terceirizada". Se for possível responsabilizar os professores pelas mazelas da educação, os gestores e suas políticas se safam...

\section{Considerações finais}

Segundo dados do Censo da Educação Básica de 2015 (BRASIL, 2016), cerca de $39 \%$ dos professores que atuam nos anos finais do ensino fundamental e no ensino médio não têm formação adequada para uma ou mais disciplinas em que lecionam. Em alguns casos, como em Física, esse número sobe para alarmantes $68,7 \%$. Essa situação calamitosa é uma combinação de pouca atratividade e pouca retenção.

No contexto atual, a profissão docente tornou-se mais atraente para uma parcela específica da população, com desempenho acadêmico relativamente baixo e pertencente às camadas mais baixas das escalas de indicadores socioeconômicos. Consequentemente, outra parcela da população, justamente aquela com maior acesso aos bens culturais e de consumo, não se tem interessado em seguir a 
profissão. Em boa parte, a formação dos professores atuantes ocorre em precárias instituições privadas de ensino superior, em sua maioria em cursos a distância. Essa formação (tanto inicial, quanto continuada) e a avaliação de professores, também não têm conseguido, claramente, contribuir com a prática cotidiana destes profissionais. Boa parte destes acaba abandonando suas escolas, ou, até mesmo, o magistério, em busca de melhores oportunidades e condições de trabalho dentro e fora dos sistemas de ensino.

A partir desta caracterização é possível concluir que existem problemas complexos a serem superados pelos sistemas educacionais.

O que procuramos discutir nesse artigo é que não é possível equacionar-se o problema sem uma abordagem de conjunto. Entre as medidas que esta revisão sugere, pode-se mencionar:

a) estabelecer políticas articuladas de atração via melhoria das condições de remuneração e trabalho;

b) considerar o background dos que, no momento, se dirigem à profissão e, portanto, alterar os cursos de formação de professores;

c) publicizar a formação docente, preferencialmente em cursos de período integral com bolsas de estudo que permitam sua frequência por alunos que efetivamente queiram dirigir-se ao magistério;

d) estabelecer política de retenção dos bons profissionais, o que implica discutir a mudança nos planos de carreira, de modo a que o bom professor permaneça como professor e seja recompensado por isso;

e) estabelecer salários crescentes para os professores que permanecerem mais tempo em atividade;

f) implantar processos de avaliação que sejam substantivos com vistas a melhorar o desempenho docente e não que criem processos competitivos que incentivam apenas uma parte do magistério.

As escolhas não são inocentes, ao se optar por enfatizar exatamente aquela faceta que permite afirmar que a culpa é do "outro", o Poder Público cria uma cortina de fumaça sobre o problema e foge de suas responsabilidades. 


\title{
Teacher policies and educational quality: a review of literature and policy indications
}

\begin{abstract}
This paper discusses the contributions of the academic debate on four dimensions related to teacher policies in Brazil: attractiveness, training, retention and evaluation. Starting from a review of works that address these dimensions, often individually or without a relationship with each other, the aim is to highlight the main problems to be resolved by public policies driven to teachers in order to improve the educational quality. The paper is divided into six parts: an introduction, which presents the importance of the teacher's issue and the challenges imposed by it on public policy; and four sections in which attractiveness, training, retention and evaluation of teachers are analyzed, respectively. The main challenges to be equated to overcome the problems discussed are synthesized at the end of the paper.
\end{abstract}

Keywords: Teacher attractiveness. Teacher's training. Teachers'retention. Teacher evaluation.

\section{Políticas para maestros y calidad de la educación: una revisión de literatura y indicaciones de política}

\section{Resumen}

Este artículo analiza las contribuciones del debate académico en cuatro dimensiones relacionadas con las politicas docentes en Brasil: el atractivo, la formación, la retención y la evaluación. De la revisión de las obras que se ocupan de estas dimensiones, a menudo aisladamente, el objetivo es resaltar los principales problemas que deben ser resueltos por las políticas públicas dirigidas a los maestros, con el fin de mejorar la calidad de la educación. Para ello, el trabajo se divide en seis partes: una introducción, que presenta la importancia de la cuestión de enseñanza y los desafios que impone a las políticas públicas; y cuatro secciones en las que se analizan el atractivo, la formación, la retención y la evaluación de los profesores, respectivamente. Al final, se sintetizan los principales desafios que deben resolverse para superar los problemas señalados.

Palabras clave: Atractivo de maestros. Retención de maestros. Formación docente. Evaluación del maestro. 


\section{Referências}

ALLIANCE FOR EXCELLENT EDUCATION - AEE. On the path to equity: improving the effectiveness of beginning teachers. Wasington, DC, 2014.

AUGUSTE, B. G.; KIHN, P.; MILLER, M. Closing the talent gap: attracting and retaining top-third graduates to careers in teaching: an international and market research- based perspective. New York: McKinsey \& Company, 2010.

BARBER, M.; MOURSHED, M. How the world's best-performing school systems come out on top. New York: Mackinsey \& Company, 2007.

BARBOSA, Andreza. Os salários dos professores brasileiros: implicações para o trabalho docente. 2011. 208 f. Tese (Doutorado em Educação Escolar) — Faculdade de Ciências e Letras de Araraquara, Universidade Estadual Paulista, Araraquara, 2011.

BARREIRA, C.; REBELO, P. V. Avaliação do desempenho docente, desenvolvimento profissional e sucesso escolar dos alunos: uma conciliação possível? In: COLÓQUIO SOBRE QUESTÕES CURRICULARES, 8., 2008, Florianópolis. Anais... Florianópolis: UFSC, 2008.

BAUER, A. É possível relacional avaliação discente e formação de professores? A experiência de São Paulo. Educação em Revista, v. 28, n. 2, p. 61-82, jun. 2012. https://doi.org/10.1590/S0102-46982012000200004

. Avaliação de desempenho de professores: pressupostos e abordagens. In: Gatti, B. A. (Org.). O trabalho docente: avaliação, valorização, controvérsias. Campinas: Autores Associados, 2013.

BIONDI, R. L.; FELÍCIO, F. Atributos escolares e o desempenho dos estudantes: uma análise em painel dos dados do Saeb. Brasília, DF: INEP, 2007.

BRASIL. Congresso Nacional. Constituição Federal de 1988. Diário Oficial da União da República Federativa do Brasil, Brasília, DF, 5 out. 1988.

. Emenda constitucional $\mathrm{n}^{\circ} 14$, de 12 de setembro de 1996. Modifica os arts. 34, 208, 211 e 212 da Constituição Federal e dá nova redação ao art. 60 do Ato das Disposições constitucionais Transitórias. Diário Oficial da União, 13 set. $1996 \mathrm{~b}$.

. Emenda constitucional $n^{\circ} 53$, de 19 de dezembro de 2006. Dá nova redação aos arts. $7^{\circ}, 23,30,206,208,211$ e 212 da Constituição Federal e ao art. 60 do Ato das Disposições Constitucionais Transitórias. Diário Oficial da União, 20 dez. 2006. 
BRASIL. Lei No 9.394, de 20 de dezembro de1996. Estabelece as diretrizes e bases da educação nacional. Diário Oficial da União, 23 dez. 1996a.

. Ministério da Educação. Câmara de Educação Básica. Resolução $\mathrm{N}^{\mathrm{o}}$ 2, de 28 de maio de 2009. Fixa as Diretrizes Nacionais para os Planos de Carreira e Remuneração dos Profissionais do Magistério da Educação Básica Pública, em conformidade com o artigo $6^{\circ}$ da Lei ${ }^{\circ} 11.738$, de 16 de julho de 2008, e com base nos artigos 206 e 211 da Constituição Federal, nos artigos $8^{\circ}, \S 1^{\circ}$, e 67 da Lei $n^{\circ} 9.394$, de 20 de dezembro de 1996, e no artigo 40 da Lei no 11.494, de 20 de junho de 2007. Diário Oficial da União, 29 maio 2009.

. Ministério da Educação. Secretaria de Educação Básica. Fundo de Manutenção e Desenvolvimento do Ensino Fundamental e de Valorização do Magistério - Fundeb. Manual de orientação. Brasília, D. F., 2004.

. Ministério da Educação e Cultura. Instituto Nacional de Estudos e Pesquisas Educacionais Anísio Teixeira. Estudo exploratório sobre o professor brasileiro: com base nos resultados do censo escolar da educação básica 2007. Brasília, DF, 2009.

. Ministério da Educação e Cultura. Conselho da Educação Superior. Relatório técnico contendo estudo sobre a atual relação ofertal demanda de cursos de graduação no Brasil, como subsídio ao Conselho Nacional de Educação para a formulação de políticas públicas que possibilitem a melhor distribuição da oferta de vagas no ensino superior de graduação. Brasília, DF, 2013.

BRASIL. Ministério da Educação e Cultura. Instituto Nacional de Estudos e Pesquisas Educacionais Anísio Teixeira. Censo escolar da educação básica 2013: resumo técnico. Brasília, DF: INEP, 2014

. Ministério da Educação e Cultura. Instituto Nacional de Estudos e Pesquisas Educacionais Anísio Teixeira. Sinopse estatística da educação básica 2015. Brasília, DF: INEP, 2016.

CASSETARI, N. Remuneração variável para professores: revisão da literatura e desdobra- mentos no Estado de São Paulo. 2010. 130 p. Dissertação (Mestrado em Educação) - Universidade de São Paulo, São Paulo, 2010.

CASSETTARI, N.; FRUTOSO, P. C.; SCALDELAI V. F. Exoneração a pedido de professores: estudo em duas redes municipais paulistas. Educação e Sociedade, v. 35, n. 128, p. 909-27, jul.-set. 2014. https:/doi.org/10.1590/ES0101-73302014096069 
CODO, W. Educação: carinho e trabalho. Brasília, DF: Vozes, 1999.

COLAZINGARI, M. O que pensam os futuros professores? Um estudo das representações dos estudantes de licenciatura e pedagogia acerca da profissão e das práticas docentes. 2015. 297p.Tese (Doutorado em Educação) -Universidade de São Paulo, São Paulo, 2015.

DARLING-HAMMOND, L. Building a system for powerful teaching and learning. In: WEHLING, R. (Org.). Building a 21st Century U.S. education system. Washington, DF: National Commission on Teaching and America's Future, 2007.

FARBER, K. Why great teachers quit: and how we might stop the exodus. California: Sage, 2010.

FERNANDES, D. Avaliação do desempenho docente: desafios, problemas e oportunidades. Córdoba: Texto, 2008.

GATTI, B. A. Avaliação de professores: um campo complexo. Estudos em Avaliação Educacional, v. 22, n. 48, p. 77-88, jan./abr. 2011.

GATTI, B. A.; BARRETTO, E. Professores no Brasil: impasses e desafios. Brasília, DF: Unesco, 2009.

GATTI, B A.; BARRETO, E. S. S.; ANDRE, M. E. D. A. Políticas docentes no Brasil: um estado da arte. Brasília, DF: Unesco, 2011.

GATTI, B. A.; NUNES, M. M. R. (Orgs.). Formação de professores para o ensino fundamental: estudo de currículos das licenciaturas em pedagogia, língua portuguesa, matemática e ciências biológicas. São Paulo: Fundação Carlos Chagas, 2009.

GATTI, B. A. et al. A atratividade da carreira docente no Brasil. Estudos e Pesquisas Educacionais, n. 1, 139-210, maio 2010.

GUSKEY, T. R. Closing the knowledge gap on effective professional development. Educational Horizons, v. 87, n. 4, p. 224-33, Sum. 2009.

INGERSOLL, R. M.; SMITH, T. M. The wrong solution to the teacher shortage. Educational Leadership, v. 60, n. 8, p. 303, May 2003.

LAPO, F. R. BUENO, B. O. Professores, desencanto com a profissão e abandono do magistério. Cadernos de Pesquisa, São Paulo, n. 118, p. 65-88, mar. 2003. https://doi.org/10.1590/S0100-15742003000100004 
LEME, L. F. Atratividade do magistério para a educação básica: estudo com ingressantes de cursos superiores da Universidade de São Paulo. 2012. 210p. Dissertação (Mestrado em Educação) -Universidade de São Paulo, São Paulo, 2012.

. Perfil e expectativa de ingressantes do curso de pedagogia da Universidade de São Paulo e a atratividade da carreira docente. 2008.90 p. Trabalho (Conclusão de curso em Pedagogia) - Universidade de São Paulo, São Paulo, 2008.

LOUZANO, P. et al. Quem quer ser professor? Atratividade, seleção e formação docente no Brasil. Estudos em Avaliação Educacional , v. 21, n. 47, p. 543-68, 2010.

MARIN, A. J.; GIOVANNI, L. M. Expressão escrita de concluintes de curso universitário para formar professores. Cadernos de Pesquisa, v. 37, n. 130, p. 15-41, jan./abr., 2007. https://doi.org/10.1590/S0100-15742007000100003

MORICONI, G. Avaliação para o ingresso e acompanhamento de iniciantes na carreira docente. In: GATTI, B. A. (Org.). O trabalho docente: avaliação, valorização, controvérsias. Campinas: Autores Associados, 2013. p. 177-228.

. Os professores públicos são mal remunerados nas escolas brasileiras? Uma análise da atratividade da carreira do magistério sob o aspecto da remuneração. 2008. 86 p. paginação. Dissertação (Mestrado em Administração Pública e Governo - Fundação Getúlio Vargas, São Paulo, 2008.

http://www.ncsu.edu/mentorjunction/text_files/teacher_retentionsymposium. pdf. Acesso em: 28 maio 2012.

NOGUEIRA, D. X. P.; JESUS, G. R.; CRUZ, S. P. Avaliação de desempenho docente no Brasil: desvelando concepções e tendências. Linhas Críticas, v. 19, n. 38, p. 13-32, jan./abr. 2013.

NOVAES, G. T. F. Padrões de desempenho na avaliação docente e profissionalismo docente. In: GATTI, B. A. (Org.). O trabalho docente: avaliação, valorização, controvérsias. Campinas: Autores Associados, 2013. p. 109-152. .

NÓVOA, A. Formação de professores e profissão docente. In: NÓVOA, A. Os professores e a sua formação. Lisboa: Dom Quixote, 1992. p. 13-33.

OLIVEIRA, R. P.; ARAÚJO, G. C. Qualidade do ensino: uma nova dimensão da luta pelo direito à educação. Revista Brasileira de Educação, n.28, 2006. 


\section{ORGANIZAÇÃO PARA COOPERAÇÃO E DESENVOLVIMENTO ECONÔMICOS - OCDE. Professores são importantes: atraindo,} desenvolvendo e retendo professores eficazes. São Paulo: Moderna, 2007.

PAUL, J. J. ; BARBOSA, M. L. A qualidade dos professores como fator de eficácia escolar. Revista Electrónica Iberoamericana sobre Calidad, Eficacia y Cambio en Educación, v. 5, n. 5, p. 92-100, 2007.

SILVA, J. L. A rotatividade docente numa escola da rede estadual de ensino. 2007. 95 p. Dissertação (Mestrado em Educação: História, Política e Sociedade) - Pontifícia Universidade Católica de São Paulo, 2007.

SOARES, J. F. et al. Exclusão instraescolar nas escolas públicas brasileiras: um estudo com dados da Prova Brasil 2005, 2007 e 2009. Brasília, DF: Unesco, 2012

VAILLANT, D. Reformas educacionais e o papel dos docentes. Revista PREALC, n. 1, jun. 2005.

VAILLANT. G. Atraer e retener Buenos profesionales en lo profesión docente: políticas em Latinoamérica. Revista de Educación, n. 340, p. 117-40, mayo-ago. 2006.

VICENTINI. P. P., LUGLI. R. G. História da profissão docente no Brasil: representações em Disputa. São Paulo: Cortez, 2009.

\section{Informações dos autores}

Adriana Bauer: Faculdade de Educação da Universidade de São Paulo (USP) e da Fundação Carlos Chagas. Docente da Faculdade de Educação da USP, Departamento de Metodologia de Ensino e Educação Comparada e Pesquisadora do Departamento de Pesquisas Educacionais da Fundação Carlos Chagas. Contato: dri.bauer@usp.br

Nathalia Cassettari: Faculdade de Educação da Universidade de Brasília (UnB). Docente da Faculdade de Educação da UnB, Departamento de Planejamento e Administração. Contato: nathalia.cassettari@gmail.com

Romualdo Portela de Oliveira: Faculdade de Educação da Universidade de São Paulo (USP). Professor Titular da Faculdade de Educação da USP, Departamento de Administração Escolar e Economia da Educação. Contato: romualdo@usp.br 